J. Lake Sci. (湖泊科学) , $2007,19(6): 670-676$

http://www. jlakes.org. E-mail:jlakes@ niglas. ac.cn

(c) 2007 by Journal of Lake Sciences

\title{
鄱阳湖退田还湖区避洪农业模式的探讨
}

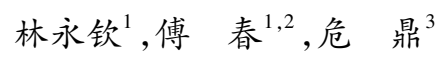

( 1 : 南昌大学管理科学与工程系, 南昌 330031)

( 2 : 南昌大学中国中部经济发展研究中心, 南昌 330047)

(3:河海大学土木学院, 南京 210098)

摘 要: 以洪灾风险为主要风险确定了鄱阳湖退田还湖区内各种避洪农业模式的风险度量指标, 并依此对各种可能模式 的效益与风险作了分析. 在此基础上, 以收益最大化和风险最小化为目标函数,建立了退田还湖区综合避洪农业模式的 多目标优化模型, 采用加权法求出非劣解, 并通过收益一风险的综合分析, 为退田还湖区避洪农业发展的风险决策提供客 观依据.

关键词:退田还湖区; 避洪农业模式;收益一风险分析;多目标优化;鄱阳湖

\section{Research on the patterns of flood avoiding agriculture in wetland restoration area in Lake Poyang}

LIN Yongqin ${ }^{1}$, FU Chun ${ }^{1,2} \&$ WEI Ding ${ }^{3}$

(1: Department of Management Science and Engineering, Nanchang University, Nanchang 330031, P. R. China)

(2: Research Center for Central China Economic Development, Nanchang University, Nanchang 330047, P. R. China)

(3: School of Civil Engineering, Hohai University, Nanjing 210098, P. R. China)

\begin{abstract}
Based on hydrological risk, the risk measurement indicators for various flood avoiding agricultural patterns are introduced in wetland restoration area in Lake Poyang. According to the values of these indicators, the benefit and risk of various flood avoiding agricultural patterns are analyzed. And then using benefit maximization and risk minimization as objective functions, a multiobjective planning model of integrated flood avoiding economic patterns is constructed. Several typical noninferior solutions to the model are generated by applying weighting method. The tradeoff analysis of benefit and risk for different noninferior solutions, which indicates that planting vegetable is a high benefit and low risk pattern but surface aquaculture is a high benefit and risk pattern, may provide objective foundation for risk decision making of flood avoiding agriculture in the wetland restoration area.
\end{abstract}

Keywords: Wetland restoration area; flood avoiding agricultural pattern; benefit and risk analysis; multiobjective optimization; Lake Poyang

长期以来,鄱阳湖围垦作为湖区人民改造自然条件、增长物质财富的主要手段,对改善湖区人民生存环 境、促进湖区经济发展、推动湖区社会进步起了重要的积极作用. 但随着围怎面积的加大,湖泊最高水位逐 年上升 ${ }^{[1,2]}$, 调蓄洪水容量大减 ${ }^{[3]}$, 使湖区洪涝灾害损失增加. 为此, 江西省政府依照国务院提出的 32 字方 针, 制定《江西省平垸行洪退田还湖移民建镇若干规定》, 从 1998 年起对鄱阳湖区、长江干流和五河 (赣江、 抚河、信江、饶河、修河) 尾问地区部分圩堤进行平垸行洪、退田还湖.

鄱阳湖区是指水文气候特征与鄱阳湖有关的南昌县、新建县、进贤县、永修县、德安县、星子县、湖口县、

* 国家自然科学基金资助 (40361003) 项目. 2006-10-11 收稿;2006-12-04 收修改稿. 林永钦,男,1975 年生,博 士研究生,讲师;E-mail:yongqin_lin@163.com. 
都昌县、波阳县、余干县、万年县、乐平市、丰城市和九江市庐山区, 总面积 $26266 \mathrm{~km}^{2}$. 鄱阳湖区退田还湖实 行退人不退田的“单退” 和退人又退田的“双退” 两种方式. 规模在 $667 \mathrm{hm}^{2}$ 以上的单退圩区,进洪水位为相 应湖口水位 $21.68 \mathrm{~m}$; 规模在 $667 \mathrm{hm}^{2}$ 以下的圩区,进洪水位为相应湖口水位 $20.50 \mathrm{~m}$. 至 2003 底, 鄱阳湖区 的退田还湖工作已经基本完成 ${ }^{[4]}$, 实现了高水还湖面积 $873.1 \mathrm{~km}^{2}$. 其中, 双退圩区总面积共 $130.7 \mathrm{~km}^{2}$; $667 \mathrm{hm}^{2}$ 以下平退圩区总面积共 $265.5 \mathrm{~km}^{2} ; 667 \mathrm{hm}^{2}$ 以上平退圩区总面积共 $476.9 \mathrm{~km}^{2}$. 本文所研究的退田 还湖区即为鄱阳湖区内的单退圩区.

实施 “平垸行洪、退田还湖” 后, 在鄱阳湖水域增长的同时, 由于人口增长的压力和社会经济发展的需 要,湖区人民群众把对鄱阳湖的压力转移到其他类型的土地上,造成了水域之外其他土地利用类型的压力 进一步增大 ${ }^{[5]}$. 因而, 解决移民生计问题、发展高效避洪的农业经济模式, 是保证鄱阳湖区可持续发展的关 键. 许多学者已就退田还湖区的避洪农业发展模式,展开了卓有成效的研究. 李阳生等 ${ }^{[6]}$ 根据区域特定的 生态环境, 景观结构, 洪涝灾害类型、特征和发生发展规律, 针对泛洪区不同地带洪灾危害程度, 以洞庭湖水 系为例, 提出了以避洪农业设计和耐涝农业生产为主要内容的减灾生态农业发展模式. 彭佩钦等 ${ }^{[7,8]}$ 在调 查分析洞庭湖区围湖层殖和湖垸农业形成的历史以及洪涝灾害规律的基础上,结合已有的经验, 提出了如 调整湖垸农业结构、发展替代农业模式、发展工业原料作物等退田还湖区农业可持续发展的对策措施. 冯 双华等 ${ }^{[9]}$ 针对湖区社会、生态协调持续发展的原则,提出了六条堤垸耕地资源可持续性及其保护对策. 刘 慧 ${ }^{[10]}$ 指出长江中游地区不合理的土地利用所引起的河湖调蓄能力的下降是加剧中游地区洪涝灾害的重要 因素, 并据此提出了中游地区减轻洪涝灾害的土地利用对策, 如编制易灾区土地利用总体规划、发展避洪农 业、建设分蓄洪区、提高土地利用率等. 类似研究成果虽然未能针对具体的避洪经济发展模式进行风险与 效益的综合定量分析, 但对于退田还湖区制定高效避洪的农业经济发展模式,具有很大的借鉴意义.

而从对鄱阳湖区圩区的实际调研来看,鄱阳湖区圩区内各种简单的“低水种养”运作模式难以保障生 产的正常进行, 未能充分解决农民生产与生活来源问题, 由此导致了移民回迁、圩堤缺口复堵以及破坏性掠 夺湿地资源等现象的存在. 因此,能否因地制宜地挖掘退田还湖区内水面与耕地的利用价值、制定合理的 激励措施提高在圩区内进行扩大再生产的积极性和收益, 已成为退田还湖、移民建镇政策能否成功的紧迫 问题. 而解决这一问题的关键在于对退田还湖区内各种具体避洪农业模式的效益与风险进行细致合理的 计算,进而寻找出收益高而风险又相对较低的综合避洪农业模式,实现退田还湖区内水土资源利用的最大 效益和社会经济的可持续发展.

\section{1 各种避洪农业模式收益与风险分析}

\section{1 风险指标选择}

洪灾风险是一种纯粹风险,只会造成损失,而基本上没有收益. 但在未受洪灾的正常年份或季节,人们 在单退圩内从事生产和经济活动, 可获得农业收人即存在收益机会 ${ }^{[11]}$. 当然在遭受洪水淹没时, 也要承受 损失. 从这个意义上讲,在圩区内从事生产和经济活动是一种投机风险问题. 由于具有纯粹风险的性质和 投机风险的特点, 同时又涉及人们的决策行为, 因此在圩内从事生产和经济活动的风险不能简单地用纯粹 风险的受损概率和投机风险的损失离散程度来衡量,而必须全面考虑农业生产的收益与损失的风险状况. 假定防洪工程风险及其技术、市场风险为定量, 则可选择进水遭受洪灾的概率 $P$ 、纯收益均值 $E(B) 、$ 洪灾 (进水) 损失均值 $E(L)$ 、纯收益的负均方差 $\sigma(B)^{-}$、损失的正均方差 $\sigma(L)^{+}$、纯收益不稳定性 $R(B)=\sigma$ $(B)^{-} / E(B)$ 作为衡量不同避洪农业模式的收益与风险指标.

为求得进水受灾概率 $P$, 首先对水位风险变量进行概率分析, 以求出一年中国家规定的分洪水位出现 的概率. 以皮尔逊 III型曲线作为水位的理论概率密度函数,把历年来的年最高水位数据从高到低排序, 进 行频率计算,算出离差系数 $C v$, 并假设偏态系数 $C s$ 分别为 $1.5 C v 、 2.0 C v 、 2.5 C v$, 绘出三条皮尔逊 III 型曲线, 用最小二乘法与目估法进行适线选择，在确定总体皮尔逊 III型曲线后,求出国家规定的分洪进水的概率：

$$
P_{1}=P\left(X \geqslant x_{p}\right)=\frac{\beta^{a}}{\Gamma(\alpha)} \int_{x_{p}}^{\alpha}\left(x-\alpha_{0}\right)^{\alpha-1} \exp \left[-\beta\left(x-\alpha_{0}\right)\right] \mathrm{d} x
$$

其中, $x_{p}$ 为国家规定的进水水位值. 
然后对水位超过 $x_{p}$ 的出现时间这一随机变量进行概率分析, 以求出在某一段时间内水位超过 $x_{p}$ 的概 率. 因难以确定其所服从的分布, 所以采用频率累积曲线近似求得在某一段时间内水位超过 $x_{p}$ 的概率. 即 根据实测序列水位超过 $x_{p}$ 的日期数据, 进行频率计算, 绘制频率累积曲线. 根据频率累积曲线可以求出在 某一段时间内水位超过 $x_{p}$ 的概率:

$$
P_{2}=P\left(x_{1} \leqslant X \leqslant x_{2}\right)
$$

式中, $x_{1} 、 x_{2}$ 为某具体模式的利用起论时间.

假设在一年中分洪进水事件与某段时间内水位超过 $x_{p}$ 的事件相互独立, 则某种具体模式当年进水受灾 的概率可以表示为:

$$
P=P_{1} \times P_{2}
$$

求得进水受灾概率 $P$ 后, 就可确定其它风险指标的计算公式 (表 1 ). 其中, $B_{1}$ 为受灾纯收益 (万元/ $\left.\mathrm{hm}^{2}\right), B_{2}$ 为不受灾纯收益 (万元 $/ \mathrm{hm}^{2}$ ), 这里, 纯收益指总收人扣除生产投人成本后的部分; $L$ 为受灾损失 (万元 $/ \mathrm{hm}^{2}$ ), 由于 $B_{1}$ 和 $B_{2}$ 为纯收益且考虑的是发生洪灾的损失, 因此不受灾的损失为 0 , 受灾损失 $L$ 为投 人的损失.

表 1 风险指标计算公式

Tab. 1 Calculation formulae for risk indicators

\begin{tabular}{cc}
\hline 风险指标 & 计算公式 \\
\hline 受灾概率 $P$ & $P=P_{1} \times P_{2}$ \\
纯收益均值 $E(B)\left(\right.$ 万元 $\left./ \mathrm{hm}^{2}\right)$ & $E(B)=P \times B_{1}+(1-P) \times B_{2}$ \\
损失均值 $E(L)\left(\right.$ 万元 $\left./ \mathrm{hm}^{2}\right)$ & $E(L)=P \times L$ \\
纯收益负均方差 $\sigma(B)^{-}\left(\right.$万元 $\left./ \mathrm{hm}^{2}\right)$ & $\sigma^{2}(B)^{-}=P \times\left(B_{1}-E(B)\right)^{2}$ \\
损失均方差 $\sigma(L)^{+}\left(\right.$万元 $\left./ \mathrm{hm}^{2}\right)$ & $\sigma^{2}(L)^{+}=P \times(L-E(L))^{2}$ \\
收益不稳定性 $R(B)$ & $R(B)=\sigma(B)^{-} / E(B)$ \\
\hline
\end{tabular}

\section{2 具体避洪农业模式分析}

在 98 洪水与退田还湖政策开始实行后, 不少学者对退田还湖区不同类型的土地的最佳利用方式进行 了研究 ${ }^{[6-8,12]}$, 结合相关研究成果,通过调研,我们总结出退田还湖区避洪农业的一些代表性模式(表 2 第 1 列). 为能够具体分析各模式的收益与风险, 下面以都昌县单退圩区为例进行说明.

各模式的产量和投人经过调研确定, 相应的生产成本 (不计劳动投人的机会成本和拦网等工程投人成 本) 和纯收益以 2000 年市场价格为基准进行核算. 由此求得各种模式的生产投入成本 $C\left(\right.$ 万元 $\left./ \mathrm{hm}^{2}\right)$ 和不 进水纯收益 $B_{2}$ (表 2$)$.

接着需确定各模式的进水受灾概率 $P$. 首先, 以都昌水文站 1952 年至 2002 年的实测数据进行频率计 算, 求得离差系数 $C v=\sqrt{\sum_{i=1}^{51}\left(K_{i}-1\right)^{2} / 50}=0.08$ ( $K_{i}$ 为模比系数), 选择偏态系数 $C s$ 分别为 $1.5 C v 、 2.0$ $C v 、 2.5 C v$ 进行频率与水位关系试算. 由目估适线与最小二乘法计算选择 $C s=2.0 C v$ 的曲线为最高洪水位 的理论概率曲线, 由此得 $667 \mathrm{hm}^{2}$ 以下圩区的分洪进水概率 (都昌水位高于湖口 $\left.0.03 \mathrm{~m}\right): P_{1}=P(X \geqslant$ $20.53)=18.2 \%$. 然后, 利用 51 年实测数据中 10 个水位超过 $20.53 \mathrm{~m}$ 的日期数据样本, 计算出在某段时 期内水位超过 $20.53 \mathrm{~m}$ 的频率 $P_{2}$ (表 3 ).

对于种植业的受灾概率, 根据生产种植时期, 由公式 $P=P_{1} \times P_{2}$ 求得; 而对于水产养殖模式,假定已经 实施拦网工程 (该工程可在满足进水要求的前提下防止鱼外游,经测算, 工程投人成本可当年回收), 则受 灾概率为 $0.76 \%$, 即最高洪水位大于 $23.00 \mathrm{~m}$ (都昌县平退圩堤平均高程) 的洪水发生概率. 由此, 求得 667 $\mathrm{hm}^{2}$ 以下圩区各模式的受灾概率 $P($ 表 2).

各模式的受灾纯收益 $B_{1}$ 和受灾损失 $L$ 按以下原则确定: 对于种草养鹅以外的模式,受灾时完全损失、 不受灾时取得全部纯收益, 即受灾纯收益 $B_{1}$ 为 $-C$ 、受灾损失 $L$ 为 $C$; 而对于种草养鹅 (第二批) 模式, 遭受 洪灾后, 鹅可圈养也可以出售,但要损失一半的投人. 综上并结合表 1 的计算公式,求得 $667 \mathrm{hm}^{2}$ 以下圩区 
各模式其他五项指标的值 (表 2).

类似地, 可求得 $667 \mathrm{hm}^{2}$ 以上圩区各模式的受灾概率及各指标值 (表 2 括号内数值).

表 2 具体避洪农业模式风险计算结果 *

Tab. 2 Calculations for risk of specific flood avoiding agricultural patterns

\begin{tabular}{|c|c|c|c|c|c|}
\hline 模式 & 种植时间 (月. 日) & 投人 $(C)$ & 纯收益 $\left(B_{2}\right)$ & 受灾概率 $(P)$ & $E(B)$ \\
\hline 一季晚稻 & $6.15-9.10$ & 0.24 & 0.52 & $18.2 \%(5.1 \%)$ & $0.38(0.48)$ \\
\hline 早稻 & $5.1-7.15$ & 0.24 & 0.20 & $14.56 \%(3.83 \%)$ & $0.14(0.18)$ \\
\hline 二季晚稻 & $8.1-11.1$ & 0.24 & 0.43 & $12.74 \%(3.83 \%)$ & $0.34(0.40)$ \\
\hline 早珍珠 & $3.4-6.27$ & 0.24 & 0.05 & $9.1 \%(1.28 \%)$ & $0.02(0.05)$ \\
\hline 早、晚稻 & / & 0.48 & 0.63 & / & $0.48(0.58)$ \\
\hline 蔬菜种植 & 9.20 - 次年 4 月底 & 0.60 & 1.08 & $1.82 \%(0)$ & $1.05(1.08)$ \\
\hline \multirow{2}{*}{ 鱼藕混养 } & \multirow{2}{*}{ 全年 } & 0.15 & 0.09 & $0.76 \%(0.76 \%)$ & \multirow{2}{*}{$1.83(2.18)$} \\
\hline & & 0.44 & 2.23 & $18.2 \%(5.1 \%)$ & \\
\hline 种草养鹅 (第一批) & 11 月 - 次年 5 月 & 1.05 & 0.98 & 0 & $0.98(0.98)$ \\
\hline 种草养鹅 (第二批) & $5-11$ 月 & 1.05 & 0.98 & $18.2 \%(5.1 \%)$ & $0.70(0.90)$ \\
\hline 种草养鹅 (两批) & / & 2.10 & 1.95 & 1 & $1.68(1.88)$ \\
\hline 水面粗养 & 全年 & 1.95 & 0.75 & $0.76 \%(0.76 \%)$ & $0.73(0.73)$ \\
\hline 水面精养 & 全年 & 2.93 & 1.61 & $0.76 \%(0.76 \%)$ & $1.58(1.58)$ \\
\hline 模式 & 种植时间 (月. 日) & $E(L)$ & $\delta(B)^{-}$ & $\delta(L)^{+}$ & $R(B)$ \\
\hline 一季睌稻 & $6.15-9.10$ & $0.044(0.012)$ & $0.265(0.163)$ & $0.084(0.051)$ & $0.695(0.338)$ \\
\hline 早稻 & $5.1-7.15$ & $0.035(0.009)$ & $0.143(0.083)$ & $0.078(0.045)$ & $1.055(0.452)$ \\
\hline 二季晚稻 & $8.1-11.1$ & $0.031(0.009)$ & $0.209(0.126)$ & $0.075(0.045)$ & $0.605(0.312)$ \\
\hline 早珍珠 & $3.4-6.27$ & $0.022(0.003)$ & $0.080(0.032)$ & $0.066(0.027)$ & $3.368(0.700)$ \\
\hline 早、晚稻 & / & $0.066(0.018)$ & $0.352(0.209)$ & $0.153(0.090)$ & $0.733(0.360)$ \\
\hline 蔬菜种植 & $9.20-$ 次年 4 月底 & E $0.011(0)$ & $0.223(0)$ & $0.079(0)$ & $0.212(0)$ \\
\hline 鱼藕混养 & 全年 & $0.081(0.023)$ & $0.953(0.593)$ & $0.167(0.107)$ & $0.521(0.272)$ \\
\hline 种草养鹅 (第一批) & 11 月 - 次年 5 月 & $0(0)$ & $0(0)$ & $0(0)$ & $0(0)$ \\
\hline 种草养鹅 (第二批) & $5-11$ 月 & $0.096(0.027)$ & $0.527(0.324)$ & $0.185(0.114)$ & $0.747(0.358)$ \\
\hline 种草养鹅( 两批) & I & $0.096(0.027)$ & $0.527(0.324)$ & $0.185(0.114)$ & $0.314(0.172)$ \\
\hline 水面粗养 & 全年 & $0.015(0.015)$ & $0.234(0.234)$ & $0.169(0.169)$ & $0.320(0.320)$ \\
\hline 水面精养 & 全年 & $0.022(0.022)$ & $0.393(0.393)$ & $0.253(0.253)$ & $0.249(0.249)$ \\
\hline
\end{tabular}

* 括号内为 $667 \mathrm{hm}^{2}$ 以上圩区的对应数据.

表 3 水位超过 $x_{p}$ 的频率

Tab. 3 Frequency of flood levels beyond $x_{p}$

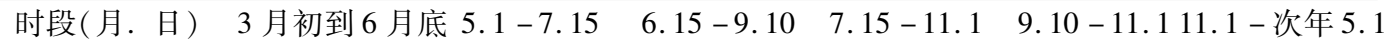

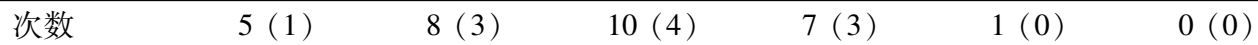

频率 $P_{2} \quad 0.50(0.25) \quad 0.80(0.75) \quad 1.00(1.00) \quad 0.70(0.75) \quad 0.10(0) \quad 0(0)$

* 括号内为 $667 \mathrm{hm}^{2}$ 以上圩区的对应数据.

由表 2 可以看出:

1) 在两类圩区的水稻种植模式中, 早珍珠与早稻的纯收益均值与收益稳定性明显不如其它模式, 不宜 推广; 一季晚稻、二季晚稻与早稻加晚稻之间各有优劣, 可根据实际需要采用其中一种或混合使用. 例如, 
$667 \mathrm{hm}^{2}$ 以下圩区因受灾概率较高, 可选择风险较小的二季晚稻模式; $667 \mathrm{hm}^{2}$ 以上圩区因受灾概率较小, 可 选择纯收益较高的早稻加晚稻模式.

2) 蔬菜种植模式是一种收益高而风险小的利用模式,应大力扶持与推广.

3) 从纯收益均值和损失均值来看,鱼藕混养模式优于种草养鹅模式,但鱼藕混养的收益稳定性小于种 草养鹅, 因而可依据投人能力进行选择. 若把种草养鹅对于预防血吸虫病的有利作用考虑进来, 则应在圩 内积极推广种草养我模式.

4) 水面精养模式的投人成本和损失均值要大于水面粗养模式,但其纯收益与收益稳定性均大于后者, 可依据圩内居民的投入能力予以推广.

\section{2 综合避洪农业模式的多目标决策}

如前所述,不同的避洪农业模式具有不同的收益一风险组合, 因而对鄱阳湖区圩区内避洪农业模式的 选择应按照整体、协调、自生及循环原则, 建立适应洪涝灾害发生规律的农业体系 ${ }^{[13]}$. 也就是考虑土地、市 场、各种投入等约束,并根据不同高程综合各种可能的避洪农业模式 ${ }^{[14]}$, 以实现收益高而风险小的利用目 标. 为此, 采用多目标优化模型, 分别对 $667 \mathrm{hm}^{2}$ 以下圩区和 $667 \mathrm{hm}^{2}$ 以上圩区的避洪农业作收益一风险的 综合分析.

\section{$2.1667 \mathrm{hm}^{2}$ 以下圩区避洪农业的收益一风险综合分析}

以都昌大唡池圩区 (总面积 $6.33 \mathrm{~km}^{2}$ ) 为例进行说明. 大唡池圩区的内湖运作水位 $15 \mathrm{~m}$,圩堤保护耕地 $300 \mathrm{hm}^{2}$ 、水面 $63.3 \mathrm{hm}^{2}$. 圩区耕地主要分布在高程 $15-22 \mathrm{~m}$ 之间, 其中, $15-18 \mathrm{~m}$ 之间面积为 $200 \mathrm{hm}^{2}$ 且地 势较为平坦,可以认为 $200 \mathrm{hm}^{2}$ 耕地在 $15-18 \mathrm{~m}$ 之间平均分布, $18-22 \mathrm{~m}$ 之间面积为 $100 \mathrm{hm}^{2}$.

以某种避洪农业模式所占的土地面积 $X_{i}(i=1, \cdots, 8$ 分别表示模式一季晚稻、早稻加晚稻、二季晚稻、 蔬菜种植、鱼藕混养、种草养我、水面粗养和水面精养) 为决策变量 (单位: $\mathrm{hm}^{2}$ ); 目标函数为湖区避洪农业 的期望纯收益最大化和风险最小化, 即:

$$
\max E B=\sum_{i=1}^{8} \alpha X_{i} \text { 和 min Risk }=\sum_{i=1}^{8} \beta_{i} X_{i}
$$

其中, $\alpha_{i} \beta_{i}$ 分别为第 $i$ 种模式的纯收益均值 $E(B)$ 、风险费用 (这里用纯收益负均方差 $\sigma(B)^{-}$表示), 具体 数值见表 2 .

为着重突出避洪农业的收益与风险问题并简化模型求解,在约束条件中暂不考虑资金、市场、劳力资源 约束与其它生产条件制约因素, 而只反映水土资源状况如面积总数、适合某种模式的面积数. 结合上一节 的讨论, 确定具体约束条件如下:

1) 在实施拦网工程后,水面可采用水面粗养方式与精养方式,即: $X_{7}+X_{8} \leqslant 63.3$;

2) $15-16 \mathrm{~m}$ 受涝严重的低洼地采用鱼藕混养模式与种草养我模式, 即: $X_{5}+X_{6} \leqslant 66.7$;

3) $16-18 \mathrm{~m}$ 的水稻种植面积约束: $X_{1}+X_{2}+X_{3} \leqslant 133.3$;

4) $18-22 \mathrm{~m}$ 之间为蔬菜种植区, 即: $X_{4} \leqslant 100$;

5 ) 决策变量非负约束.

采用加权法 ${ }^{[15]}$ 求得模型的非劣解 (表 4 ).

平均纯收益的增加伴随着风险的提高, 因而难以直观比较方案的优劣 (表 4). 为了从收益最大与风险 最小两方面进行权衡, 可引人方案 $i$ 到方案 $i+1$ 的收益与风险费用的边际替代率 $M R S_{i i+1}$ 的概念, 即收益减 少一个单位所换取的风险费用的减少数量, 其计算公式为:

$$
M_{R S} S_{i i+1}=\frac{\text { Risk }_{i}-\text { Risk }_{i+1}}{E B_{i}-E B_{i+1}} \quad i=1,2, \cdots, L
$$

通过计算,方案 1 到方案 2 的边际替代率 $M R S_{12}$ 为 $2.84, M R S_{23}=1.02, M R S_{34}=0.61, M R S_{45}=0.31$, $M R S_{56}=0.25, M R S_{67}=0.21$. 因此,较佳的综合避洪农业发展模式是方案 2 所代表的生产方式, 即采取早稻 加晚稻 $\left(133.3 \mathrm{hm}^{2}\right)$ 、蔬菜种植 $\left(100 \mathrm{hm}^{2}\right)$ 、种草养鹅 $\left(66.7 \mathrm{hm}^{2}\right)$ 和水面精养 $\left(63.3 \mathrm{hm}^{2}\right)$ 模式, 这与第 2 节中 对各种具体避洪农业模式的分析结果相一致. 
表 $4667 \mathrm{hm}^{2}$ 以下圩区优化模型的非劣解

Tab. 4 Non-inferior solutions to the optimization model for restoring region under $667 \mathrm{hm}^{2}$

\begin{tabular}{ccccccccccc}
\hline 方案(非劣解) & $X_{1}$ & $X_{2}$ & $X_{3}$ & $X_{4}$ & $X_{5}$ & $X_{6}$ & $X_{7}$ & $X_{8}$ & $E(B)$ & Risk \\
\hline 1 & 0 & 133.3 & 0 & 100 & 66.7 & 0 & 0 & 63.3 & 391.06 & 157.66 \\
2 & 0 & 133.3 & 0 & 100 & 0 & 66.7 & 0 & 63.3 & 381.05 & 129.25 \\
3 & 0 & 0 & 133.3 & 100 & 0 & 66.7 & 0 & 63.3 & 362.39 & 110.19 \\
4 & 0 & 0 & 0 & 100 & 0 & 66.7 & 0 & 63.3 & 317.07 & 82.33 \\
5 & 0 & 0 & 0 & 100 & 0 & 0 & 0 & 63.3 & 205.01 & 47.18 \\
6 & 0 & 0 & 0 & 100 & 0 & 0 & 0 & 0 & 105.00 & 22.30 \\
7 & 0 & 0 & 0 & 0 & 0 & 0 & 0 & 0 & 0 & 0 \\
\hline
\end{tabular}

\section{$2.2667 \mathrm{hm}^{2}$ 以上圩区避洪农业的收益一风险综合分析}

以都昌县南溪圩区为例进行说明. 南溪圩区位于都昌县城东南部 $26 \mathrm{~km}$, 面临鄱阳湖, 地理位置为东经 $116^{\circ} 15^{\prime}-116^{\circ} 22^{\prime}$ 、北纬 $79^{\circ} 12^{\prime}-79^{\circ} 17^{\prime}$, 集雨面积 $25 \mathrm{~km}^{2}$, 保护人口 26460 人, 保护水面 $153 \mathrm{hm}^{2}$ (高程 $10-$ $13 \mathrm{~m}$ ). 保护耕地 $947 \mathrm{hm}^{2}$, 其中, $12-15 \mathrm{~m}$ 低滩的面积为 $277 \mathrm{hm}^{2}, 15-17 \mathrm{~m}$ 之间面积为 $206 \mathrm{hm}^{2}, 22-22.5$ $\mathrm{m}$ 之间面积为 $464 \mathrm{hm}^{2}$.

采用与 2.1 小节相同的决策变量和目标函数,结合南溪圩区的情况, 确定约束条件为:

1) 水面采用水面粗养方式与精养方式,即: $X_{7}+X_{8} \leqslant 153$;

2) $12-15 \mathrm{~m}$ 受涝严重的低滩采用鱼藕混养模式与种草养我模式, 即: $X_{5}+X_{6} \leqslant 277$;

3) $15-17 \mathrm{~m}$ 的水稻种植面积约束: $X_{1}+X_{2}+X_{3} \leqslant 206$;

4) $22-22.5 \mathrm{~m}$ 之间为水稻种植和蔬菜种植区, 即: $X_{1}+X_{2}+X_{3}+X_{4} \leqslant 464$;

5 ) 决策变量非负约束.

采用加权法求得模型的非劣解 (表 5). 通过计算, 方案之间的边际替代率 $M R S_{12}=0.90, M R S_{23}=0.46$, $M R S_{34}=0.31, M R S_{45}=0.25, M R S_{56}=0.25, M R S_{67}=0.17$. 因此, 若不考虑粮食产量的下限约束和蔬菜的市场 约束, 则较佳的综合避洪农业发展模式是方案 2 所代表的生产方式, 即采取早稻加晚稻 $\left(206 \mathrm{hm}^{2}\right)$ 、蔬菜种 植 $\left(464 \mathrm{hm}^{2}\right)$ 、种草养鹅 $\left(277 \mathrm{hm}^{2}\right)$ 和水面精养 $\left(153 \mathrm{hm}^{2}\right)$ 模式.

\section{表 $5667 \mathrm{hm}^{2}$ 以上圩区优化模型的非劣解}

Tab. 5 Non-inferior solutions to the optimization model for restoring region beyond $667 \mathrm{hm}^{2}$

\begin{tabular}{ccccccccccc}
\hline 方案(非劣解) & $X_{1}$ & $X_{2}$ & $X_{3}$ & $X_{4}$ & $X_{5}$ & $X_{6}$ & $X_{7}$ & $X_{8}$ & $E B$ & Risk \\
\hline 1 & 0 & 206 & 0 & 464 & 277 & 0 & 0 & 153 & 1466.2 & 267.44 \\
2 & 0 & 206 & 0 & 464 & 0 & 277 & 0 & 153 & 1383.1 & 192.93 \\
3 & 0 & 0 & 206 & 464 & 0 & 277 & 0 & 153 & 1346.0 & 175.83 \\
4 & 0 & 0 & 0 & 464 & 0 & 277 & 0 & 63.3 & 1263.6 & 149.88 \\
5 & 0 & 0 & 0 & 464 & 0 & 277 & 0 & 0 & 1021.9 & 89.75 \\
6 & 0 & 0 & 0 & 464 & 0 & 0 & 0 & 0 & 501.1 & 0 \\
\hline
\end{tabular}

\section{3 结论}

在 1998 年洪水与退田还湖政策开始实行后, 不少学者对退田还湖区内土地的最佳利用方式进行了很 有成效的研究. 但大部分研究考虑的主要是某一具体土地利用方式的效益, 而忽略了在一定程度上更为重 要的洪灾风险问题. 为此,本文以水位大小风险因子、最高水位出现的时间风险因子作为洪灾风险变量, 依 据国家规定的鄱阳湖 $667 \mathrm{hm}^{2}$ 以下和 $667 \mathrm{hm}^{2}$ 以上两种平退圩区的进水水位值,对各种具体避洪农业模式的 风险与收益进行了定量分析. 分析结果表明, 蔬菜种植模式因其收益高、风险小, 值得大力扶持与推广; 早 
珍珠与早稻相对其它模式收益低、风险大, 不宜进行推广; 而其它水稻种植模式之间、鱼藕混养与种草养我鸟 模式之间、水面利用模式之间均是收益的增加伴随着风险的增大, 须结合圩区的实际情况和圩内居民的投 人能力进行选择、推广.

另一方面, 除了根据各模式的收益与风险进行选择外, 退田还湖区避洪农业的发展还需要考虑不同高 程、不同类型土地的差异, 综合各种不同的避洪农业模式. 因此, 本文又将鄱阳湖圩区避洪农业的期望收益 最大化和风险最小化作为目标函数, 分别以都昌 $667 \mathrm{hm}^{2}$ 以下平退圩区 (大泟池圩区) 和 $667 \mathrm{hm}^{2}$ 以上平退 圩区 (南溪圩区) 为例, 对各种具体模式的综合利用进行了定量分析, 据此确定出了效益大风险小的综合避 洪农业发展模式, 即结合采用早稻加晚稻、蔬菜种植、种草养鹅和水面精养模式.

虽然文中的数值例子主要针对都昌县的平退圩区, 但所采用的针对各种具体避洪农业模式的效益与风 险分析方法、以及综合避洪农业模式多目标决策的分析方法, 可以在结合其它 $667 \mathrm{hm}^{2}$ 以下圩区和 $667 \mathrm{hm}^{2}$ 以上圩区的具体情况与特点的基础上进行应用, 从而为鄱阳湖退田还湖区避洪农业发展的措施制订和风险 决策提供客观依据.

\section{4 参考文献}

[1] 闵 骞. 近 50 年鄱阳湖形态和水情的变化及其与围垦的关系. 水科学进展, 2000,11(1):76-81.

[2] 胡细英, 朱宏富. 三峡工程与鄱阳湖区重要城市防洪. 江西师范大学学报 (自然科学版), 1998, 22 (4) :365-370.

[3] Shankman David, Liang Qiaoli. Landscape changes and increasing flood frequency in China's Lake Poyang region. The Professional Geographer, 2003, 55(4) : 434-445.

[4] 吴敦银, 李荣昉, 王永文. 鄱阳湖区平垸行洪退田还湖后的防洪减灾形势分析. 水文, 2004,24(6):26 -31 .

[5] 蔡海生, 朱德海, 赵小敏. 1998 年前后鄱阳湖区土地利用变化分析. 中国农业大学学报,2005,10(6): $88-93$

６6］李阳生,李绍清, 李达模. 避洪农业与生态农业减灾. 农业现代化研究, 1999,20(4):226-228.

[7] 彭佩钦, 赵青春, 蔡长安. 洞庭湖区的湖垸农业与可持续发展对策. 生态环境, 2004,13 (1): 139 -141 .

[8] 彭佩钦, 蔡长安, 赵青春. 洞庭湖区的湖垸农业洪涝灾害与退田还湖. 国土与自然资源研究, 2004, (2) $: 23-25$.

[9] 冯双华,谢小立, 肖国樱. 洞庭湖区堤垸耕地资源可持续性及其保护对策. 水土保持通报, 2004,24 (6) $: 82-85$.

[10] 刘 慧. 长江中游地区洪涝灾害的土地利用思考. 长江流域资源与环境, 2004,13(6):616-619.

[11] 毛端谦,刘春燕. 鄱阳湖湿地生态保护与可持续利用研究. 热带地理,2002,22(1):24-27.

[12] 余玉平, 熊多根, 万美莲等. 南昌县湖区避洪农业生产中几种高效模式的应用. 江西农业科技,2002, (3) $: 7-8$.

[13] 王克林. 洞庭湖区湿地生态功能退化与避洪耐涝高效农业建设. 长江流域资源与环境, 1999,8 (2): $191-197$.

[14] 罗先诚,郑 林, 钟业喜. 鄱阳湖湿地资源及保护利用. 江西师范大学学报 (自然科学版), 2001,25 (4) :369-373.

[15] 陈 珽. 决策分析. 北京:科学出版社, 1987:157-165. 